\title{
ARQUITECTURA DE TRADICIÓN FENICIA EN CARMONA (SEVILLA)
}

\section{ARCHITECTURE OF PHOENICIAN TRADITION IN CARMONA (SEVILLA)}

\author{
por \\ MARÍA BELÉN / JOSÉ LUIS ESCACENA / ROCÍO ANGLADA \\ ALEJANDRO JIMÉNEZ / MARÍA DEL ROSARIO PARDO /ALMUDENA PASCUAL DEL \\ POBIL
}

RESUMEN: Se estudia en el presente trabajo un muro de tradición fenicia localizado en Carmona (Sevilla), perteneciente al tipo conocido como «muro de pilares». La posición estratigráfica en que se halló y el análisis del contexto arqueológico fechan dicha construcción en el siglo VI a.C.

Se compara con estructuras orientales y con otros ejemplos documentados durante los últimos años en Andalucía occidental.

\begin{abstract}
In this work a wall of phoenician tradition is analysed. This masonry, located at Carmona (Seville) and belonging to the type known as building with ashlar piers, was found in an archaeological context of the VI ${ }^{\text {th }}$ century B.C.

We compare this wall with eastern parallels and with other examples registred during the last years in western Andalusia.
\end{abstract}

\section{INTRODUCCIÓN}

La riqueza del patrimonio arqueológico de la ciudad de Carmona (fig. 1) ha llevado a la administración autonómica y al Ayuntamiento de la ciudad a poner en ejecución un plan de protección de dicho patrimonio. De acuerdo con las normas cautelares dictadas al efecto, desde 1985 se vienen realizando excavaciones preventivas en todos los solares del casco urbano para los cuales se pide permiso de construcción. Estos trabajos generan tal volumen de documentación que su estudio en profundidad difícilmente puede ser acometido por los mismos técnicos arqueólogos que realizan las excavaciones y, generalmente, de las numerosas intervenciones realizadas hasta el momento, no poseemos otra información que los sucintos informes que se recogen en los volúmenes del Anuario Arqueológico de Andalucía.

La preocupación del equipo que dirige $\mathrm{R}$. Lineros por poner los datos de que disponen al servicio de la comunidad científica, propició la firma de un convenio de colaboración entre el Excmo. Ayuntamiento 
de Carmona y el Departamento de Prehistoria y Arqueología de la Universidad de Sevilla, que tiene como finalidad el fomento de la investigación arqueológica en la ciudad. Al amparo de dicho convenio se han iniciado ya algunos trabajos sobre temas específicos, en el marco de un proyecto de miras más amplias que pretende analizar las manifestaciones arqueológicas de la presencia fenicia en la región de Carmona y su influencia sobre la comunidad autóctona. Uno de estos trabajos es el que presentamos en estas páginas.

Tiene por objeto estudiar una estructura de construcción que los especialistas conocen como «muro de pilares».

\section{EL MURO DE PILARES DE LA EXCAVACIÓN DE C/HIGUERAL $\mathbf{N}^{\circ} \mathbf{2}^{1}$}

\subsection{Contexto estratigráfico}

La construcción que estudiaremos se halló en el curso de una excavación practicada en 1987 en el solar $\mathrm{n}^{\circ} 2$ de la c/ Higueral de Carmona (Sevilla), situado al norte de la ciudad, a escasos metros del escarpe del alcor y próximo a los sondeos que dirigieron Carriazo y Raddatz en 1959(1960) y Pellicer en 1980 (Pellicer y Amores, 1985) (fig. 2). Éstos y otros estudios estratigráficos ${ }^{2}$, perfilan esta zona como una de las de mayor interés para la investigación del asentamiento perromano.

La excavación se realizó en una cuadrícula de 4 metros de lado limitada al espacio y profundidad $(4,56$ metros) de uno de los pozos de cimentación del edificio a construir. El informe de la intervención arqueológica se publicó en su momento (Cardenete y otros, 1990), de ahí que no insistamos aquí más que en la descripción de aquellas unidades de estratificación más directamente relacionadas con el muro de pilares.

Se identificaron en total 61 Unidades Estratigráficas (UUEE) ${ }^{3}$ (figs. 3 y 4 ) de las cuales 24 corresponden a etapas modernas o contemporáneas, 9 se clasificaron como medievales islámicas (UUEE $\mathrm{n}^{\circ} \mathrm{s}$. 25-31 y 43-44), 4 romanas (UUEE 32-35), 12 ibéricas (UUEE 36-42 y 45-49 y 61) y las 11 más antiguas (UUEE 50-60) se fecharon en el siglo VI a.C.

Las unidades de estratificación 50-53 designan los distintos tramos y la cimentación de la estructura constructiva objeto de este trabajo. La 50 es una unidad de estratificación vertical.documentada a profundidades comprendidas entre 206 y $304 \mathrm{cms}$. Tiene una potencia media de $100 \mathrm{cms}$. y corresponde al tramo de mampostería del muro que estudiamos. Dicho muro posee una orientación de 148 grados centesimales y estuvo adosado a un paño de sillares que debió desmontarse en algún momento para aprovechar la piedra en otras construcciones. Esta unidad proporcionó escasos fragmentos cerámicos.

La unidad 51 se localizó entre 284 y $392 \mathrm{cms}$. de profundidad. Tiene una potencia media de $80 \mathrm{cms}$. y corresponde a un segundo tramo del muro que presenta una orientación de 155 grados centesimales. Alternan en él paños de mampostería y sillares; estos últimos aparecieron a una profundidad de $338 \mathrm{cms}$.

1. Agradecemos la colaboración de los técnicos arqueólogos del Ayuntamiento de Carmona Dña. R. Cardenete, Dña. M.T. Gómez, D. R. Lineros y Dña. I. Rodríguez, que ordenaron los materiales que debíamos estudiar y nos facilitaron los originales de las figuras 3 a 6 .

2. En 1987, Mª S. Gil de los Reyes (1990) dirigió las excavaciones en el nº 3 de la misma Plazuela del Higueral, obteniendo una secuencia estratigráfica que se inicia en algún momento del siglo VI y se interrumpe a fines del IV o principios del III a.C., para continuar de nuevo ya en época moderna.

3. «Los trabajos de excavación fueron informados mediante aplicación del método Harris, con las restricciones propias derivadas de la falta de mano de obra especializada»: Cardenete y otros, 1990,257. 
Se diferenció como unidad 52 la cimentación del muro. A una profundidad de entre 392 y $440 \mathrm{cms}$ y con una potencia media de $50 \mathrm{cms}$., está igualmente construida alternando un paño de mampostería y otro de sillares, coincidiendo verticalmente con los tramos de la unidad 51. El primero consta de tres hiladas de piedra del alcor, de mediano tamaño, calzadas por otras más pequeñas; el único sillar documentado mide $47 \mathrm{cms}$. de altura (fig. 5).

Se llamó unidad 53, finalmente, a la zanja de cimentación del muro, que se supuso de las mismas medidas que el cimiento, entre 392 y $440 \mathrm{cms}$. de profundidad (máx. y mín.), al haber sido destruida por las unidades de estratificación 29 y 44, que se fechan en época medieval y que corresponden, respectivamente, a una zanja para extracción de material de construcción y a un pozo negro.

Como unidades de estratificación inmediatamente posteriores al muro de pilares se identificaron las numeradas del 36 al 42, del 45 al 47, la 49 y la 61, y como anteriores las unidades 54-60. La estructura de cimentacion que los excavadores llamaron UE 45 estaba adosada al tramo de mampostería del muro de pilares; pero tal vez ambas tuvieron un uso coetáneo. Ninguna de la dos apareció asociada a UUEE horizontales, de modo que su cronología tiene que establecerse entre la que corresponde, para el momento más antiguo, a la UE 57, que resulta alterada por una y otra, y, para el más reciente, a la de la UE 61, que se forma tras el abandono de ambas. Esta última es una unidad de estratificación horizontal positiva ${ }^{4}$ documentada entre 316 y $376 \mathrm{cms}$. de profundidad, con una potencia media de $40 \mathrm{cms}$. Se trata de una capa de formación artificial y deposición rápida, compuesta de tierra rojiza de textura arenosa en la que destaca la presencia de restos de adobes y piedra tosca.

La UE 56 corresponde a la base de la cimentación de un muro que probablemente fue arrasado en época medieval con el fin de recuperar piedra para la construcción, como parece indicar la presencia de una gran fosa (UE 29). Estratigráficamente, esta UE 56 se localiza bajo el muro de pilares, pero, de acuerdo con el registro de campo, los excavadores opinan que la superestructura original pudo adosarse al tramo de sillares (UE 51) y estar en uso al mismo tiempo.

La zanja de cimentación de la estructura 56 (UE 54) destruyó parcialmente las dos unidades inferiores detectadas en esta secuencia, que quedó interrumpida por las razones expuestas más atrás. Corresponden al hogar (UE 59) y al pavimento (UE 60) de una habitación cuya constatación quedó incompleta.

\subsection{Descripción}

La estructura de que tratamos discurría de E-O a lo largo de los 4 metros de la cuadrícula, adentrándose en los perfiles correspondientes (fig. 5). Tiene $110 \mathrm{cms}$. de anchura y 230 de altura, de los cuales $50 \mathrm{cms}$. corresponden a la cimentación. Presenta un aparejo mixto de sillares y de mampostería, y, en el tramo que la excavación permitió documentar, se constató la existencia de un machón de sillares tallados en calcarenita de cantera local formado por hiladas superpuestas de, al menos, 3 sillares unidos en seco, dos a soga y uno a tizón, de 106 x 64 x 40 cms., 138 x 56 x 40 cms. y $112 \mathrm{cms}$. de largo documentado por 60 cms. de anchos.

El machón había sido desmontado a excepción de la hilada inferior. Una junta de lajas y piedras del alcor, trabadas con barro compacto de color rojo, lo unía a un paño de mampostería que se conservaba todavía en una altura de $180 \mathrm{cms}$. En su construcción se utilizó igualmente piedra del alcor trabada con

4. Esta unidad no está reseñada en el informe preliminar, pero sí advierten los autores la posibilidad de que la que describen como UE 57 se compusiera, en realidad, de dos unidades diferentes: Cardenete y otros, 1990, 262.

5. Este sillar desaparecía en el perfil $\mathrm{W}$ de la cuadrícula. 
barro anaranjado, de tamaño medio (entre $20-40 \mathrm{cms}$.) en las dos caras y más menuda (en torno a $15 \mathrm{cms}$.) en el interior. El frente de las piedras utilizadas en los paramentos se retocó hasta conseguir una superficie regular, y se calzaron unas con otras con ripio (fig. 6). La cimentación, que alcanza una potencia media de $50 \mathrm{cms}$., alterna igualmente mampostería y sillares, uniéndose las dos fábricas con una junta de piedras pequeñas cementadas con barro rojo. Esta junta está claramente reforzada en las zonas que soportan mayor presión y peso. Al parecer, se excavó una zanja de cimentación, pero desconocemos sus características por las razones apuntadas más arriba.

\subsection{Cronología}

El análisis cronológico relativo al muro que tratamos se basará en el estudio de los materiales cerámicos contenidos en las unidades estratigráficas delimitadas durante el proceso de excavación, en especial los de aquellas que tienen relación directa con el momento de construcción de la referida estructura muraria, si bien se anotarán unas cuantas precisiones también sobre la datación de los momentos de uso y destrucción. Abordar dicho análisis a través de la referencia directa a paralelos localizados en muchas de las estratigrafías protohistóricas de Andalucía occidental, llevaría a ofrecer fechas en muchos casos contradictorias, sobre todo porque algunas de estas secuencias han experimentado en la literatura científica revisiones importantes con posterioridad a su publicación. Valga como ejemplo el sondeo llevado a cabo por Carriazo y Raddatz en 1959 en la propia Carmona (Carriazo y Raddatz, 1960), ya corregido en sus aspectos cronológicos primero por el mismo traductor de la versión española de la correspondiente memoria de excavación, L. Monteagudo (Carriazo y Raddatz, 1960: nota 20), y después por E. Cuadrado (1969: 280-282), M. Pellicer (1969: 300 y 1976-78: 11), H. Schubart (1971: 169), A. Arribas y O. Arteaga (1975: 23), J.L. Escacena (1987a: 283-285; 1987b: 80-83 y 1989: 445-446), A. Caro (1989: 17) y J.L. Escacena y M. Belén (1991: 16). De ahí que hayamos optado por tamizar la datación de nuestros materiales a través de la modificación propuesta por una serie de trabajos compilados en trabajos recientes sobre la Protohistoria de Andalucía (Belén y Escacena, e.p.a; Escacena, 1987b: 43-106 y Escacena y Belén, 1991).

La fecha de realización del muro de pilares puede deducirse de la cronología aportada por los materiales más recientes de la UE 57, una capa que se depositó en el hábitat claramente con anterioridad al levantamiento de la construcción. Dicha unidad contiene entre sus testimonios cerámicos parte de un pithos -del que se conserva el borde y el arranque de un asa- que corresponde al tipo que en la Baja Andalucía se decoró muchas veces con temas figurativos pintados (fig. 11:5). De hecho, dos fragmentos amorfos pertenecientes a esta misma clase de vasos, y en los que parecen estar representados capullos de loto, se hallaron en la misma UE (figs. 11:6 y 7). Paralelos para esta cerámica se encuentran en los yacimientos más próximos a Carmona sobre todo durante el siglo VI a.C., según puede observarse en Montemolín (Chaves y De La Bandera, 1986 y e.p.) y Setefilla (Aubet, 1989: 308; Aubet y otros, 1983: 115; Escacena, 1979-80; Murillo, 1989), si bien en la misma Carmona se documentan desde el siglo VII a.C. en el sondeo realizado por Pellicer y Amores (1985: 160), y en Doña Blanca existe ya algún vaso decorado de esta forma en el siglo VIII a.C. ${ }^{6}$ Coinciden con estas mismas fechas los paralelos de algunas piezas en barniz rojo del mismo contex to estratigráfico (fig. 11:2).

La cronología de la UE 57 podría delimitarse aún con más precisión mediante el estudio de la UE 58, inmediatamente infrapuesta. Esta otra capa contenía entre sus materiales más significativos urnas del tipo «Cruz del Negro», cerámicas de barniz rojo y ánforas. Las primeras (figs. 12:13 y 14) tienen paralelos en

6. Comunicación oral del excavador (Prof.D. Ruiz Mata), a quien agradecemos la noticia. 
la misma Carmona durante el siglo VII a.C. (Pellicer y Amores, 1985: fig. 59:j-1). El plato de barniz rojo con acanaladura en el borde de esa misma UE (fig. 12:6) tiene también en el sondeo CA-80/A una datación de mediados de ese siglo (Pellicer y Amores, 1985: fig. 24:12). La boca de ánfora de la figura 13:26 se data en el Cerro Macareno entre los siglos VII y VI a.C. (Pellicer y otros, 1983: fig. 82:939 y 795) y en Carmona a finales del VII (Pellicer y Amores, 1985: fig. 26:15A y 23:15B). Los paralelos del ánfora de la figura 13:28 tienen una cronología amplia entre los siglos VI y III a.C. (Pellicer y otros, 1983: fig. 83:1069).

El propio muro de pilares (UUEE 50-52) contenía entre sus elementos constructivos dos fragmentos de cerámica, uno de los cuales corresponde a la boca de un ánfora (fig. 9) del tipo fechado en el Cerro de la Cabeza de Santiponce durante el siglo VI a.C. (Domínguez de la Concha y otros, 1988: fig. 37B), en el corte CA-80/A de Carmona a fines de dicha centuria (Pellicer y Amores, 1985: fig. 29.3 y 4) y en el Macareno hasta en el tercer cuarto del siglo V a.C. (Pellicer y otros, 1983: fig. 5:1269b).

Los testimonios hasta ahora analizados ofrecerían de momento una fecha post quem para la fabricación del muro. En cambio, el límite cronológico ante quem vendría indicado fundamentalmente por los materiales de la UE 61, que se interpreta como la deposición de una capa de relleno acumulada a partir de la puesta en funcionamiento de la estructura arquitectónica a la que perteneció el muro de pilares. En consecuencia, la documentación más antigua registrada en la referida UE 61 podría utilizarse en principio para obtener mayor precisión cronológica.

Entre tales testimonios figura un ánfora (fig. 8:23) datable entre el siglo $\mathrm{V}$ y la primera mitad del IV a.C., con paralelos en el Cerro de la Cabeza de Santiponce y en Doña Blanca (Rodero, 1990: fig. 50 y 41 .C), así como en el Cerro Macareno (Pellicer y otros, 1983: fig. 50:1269.e). Algo más antigua puede ser la fecha de unos cuencos de cerámica gris con el borde engrosado (figs. 8:15 y 18), aunque esta forma carece de mayor precisión cronológica en el conjunto de materiales cerámicos orientalizantes (Belén, 1976: 379383; Caro, 1989: 172-173; Roos, 1982: 61, fig. 4).

Si bien las unidades estratigráficas relacionadas contextualmente con el muro de pilares contenían otros muchos testimonios cerámicos (figs. 7-13), teniendo como base la documentación hasta ahora reseñada, que resulta la más significativa a la hora de procurar una cronología relativamente precisa, la construcción que estudiamos puede llevarse a la segunda mitad del siglo VI a.C., en coincidencia con la datación ya adelantada por los excavadores en una primera valoración de conjunto de los trabajos de campo (Cardenete y otros, 1990: 261). Esta sería la fecha central de la interfacies-superficie entre las UUEE 61 y 57.

Desde que se alzó este muro, su uso debió continuar en alguna medida mientras sobresalía de la superficie del suelo, es decir, durante el resto de los tiempos prerromanos, procediéndose a su desmonte parcial en época romana según revela la UE 35. El sector de pilares de esta construcción (UE 51), respetado aún en época antigua, sufrió en cambio una destrucción significativa por la población islámica, que lo explotó en calidad de auténtica cantera, como de hecho sugiere la UE 29, que es una trinchera de saqueo (Cardenete y otros, 1990: 257-259).

\section{LOS MUROS DE PILARES EN LA ARQUITECTURA PRERROMANA DE ANDALUCÍA}

A poco de publicarse el primer trabajo monográfico en el que los muros de pilares quedaban caracterizados definitivamente como un recurso arquitectónico propio del mundo fenicio y de su ámbito de infuencia (Elayi, 1980), se daba a conocer en Huelva el primer ejemplo de tal técnica constructiva en el extremo Occidente. Durante la campaña de 1978 en el Cabezo de San Pedro, se documentaba una construcción que alterna un pilar de sillares a soga y tizón con tramos de mampostería. La estructura rellenaba una pequeña vaguada, impidiendo tal vez que las tierras desprendidas de la parte más alta del 
Cabezo perjudicaran a los que habían construido sus chozas en la ladera. La obra se fechó en la primera mitad del siglo VIII a.C., convirtiéndose así en el muro de pilares más antiguo fuera de los territorios orientales (Fernández Jurado, 1991: 170).

Por entonces, los fenicios fundaban los primeros asentamientos estables en la costa malagueña y en la bahía de Cádiz, y empezaban a organizar la infraestructura comercial que justifica en parte su presencia en la Baja Andalucía. La obra de San Pedro, en un asentamiento que tardará todavía algún tiempo en adquirir una auténtica estructura urbana, se interpretó como un regalo destinado a ganar las voluntades de quienes controlaban una considerable riqueza minera (Fernández Jurado, 1988-89: 286).

Por las mismas fechas, en las excavaciones de Niebla, también en la provincia de Huelva, se descubría otra estructura construida con la misma técnica de alternar pilares de sillares y mampostería. Esta, en cambio, parece, más que muro defensivo como en principio se pensó (Belén y otros, 1983: 976), una pared de recinto, o bien el muro de fachada de algún edificio importante. Se ha fechado a mediados del siglo II a.C., y representa por ello el mejor ejemplo de la perduración en occidente hasta época republicana de tales técnicas de construcción (Belén y Escacena, e.p.b). La zona del asentamiento en que se practicó la excavación ocupa un extremo del tell que domina el vado del río Tinto y los caminos y veredas de carne que discurren cerca de la ciudad. Esto explica que en época histórica se haya levantado junto a la Puerta de Sevilla el alcázar de la villa. Los resultados de los trabajos de campo ${ }^{7}$ permiten sospechar que en distintas etapas de la Antigüedad este solar situado al pie del castillo de los Guzmanes albergó instalaciones relacionadas con la defensa del lugar.

El muro de Carmona que estudiamos aquí es el más reciente de los ejemplos de esta técnica de construcción que se han dado a conocer, pero posiblemente no será el último. Su grosor parece demasiado grande para lo que suele darse en estructuras habitacionales, de ahí que los excavadores se inclinaran por considerarlo un muro defensivo construido en la segunda mitad del siglo VI a.C. (Cardenete y otros, 1990: 263). Su fábrica no responde exactamente a ninguno de los tipos de muros de pilares orientales recogidos por Elayi (1980) y Sharon (1987), pero sí queda muy próximo a alguno de ellos.

El tipo B de Elayi (1980: 168, fig.2a) engloba estructuras con pilares de tres sillares por hilada, uno a soga y dos a tizón (fig. 14:1 y 4). Los pilares que caracterizan el tipo C (Elayi, 1980: 168, fig. 2c) están levantados igualmente con hiladas de tres sillares, que, como en Carmona, están colocados uno a tizón, alternando su posición en cada hilada, y dos a soga, con la diferencia de que entre los dos sillares a soga que dan a cada uno de los paramentos, queda un trasdos ${ }^{8}$ que se rellena de piedra suelta.

El autor documenta también otros ejemplos de fábrica semejante a la de Carmona pero con el pilar más largo, pues se han colocado sillares a tizón en un extremo o en los dos (fig. 14:2 y 3). Las circunstancias de la excavación impidieron comprobar en el caso que nos ocupa si el pilar era más amplio, en cuyo caso podría aproximarse a este último tipo, o bien había quedado prácticamente al descubierto, permaneciendo bajo el testigo sólo unos centímetros del extremo del mismo.

En cuanto a la sistematización de Sharon (1987: fig. 2), el tipo d1 es el que presenta mayores analogías, sin ser idéntico. La diferencia principal está en que entre los dos sillares a soga que dan a cada uno de los paramentos, queda un espacio hueco que no existe en el muro que aquí estudiamos.

Cada uno de los tres ejemplos citados de Andalucía reúne las características de lo que se conoce como «muro de pilares» en los trabajos sobre arquitectura fenicia, pero presenta diferencias con los otros.

7. Excavaciones dirigidas por D. Rodrigo de Balbín que se publicarán pronto.

8. Seguimos la definición de Juan de Villanueva (1984: 78): «Llámase trasdos al lado contrario al paramento, cuando la piedra no llena el grueso de la pared, sino que en lo interior se une con otra piedra». 
El pilar del muro de San Pedro sólo tiene un paramento visto, en tanto que el interior se adosa a la pared del cabezo, rellenándose con piedra el espacio intermedio. Tiene una longitud de 1,17 $\mathrm{mts}$. en el centro, $1 \mathrm{mt}$. de anchura y $2,10 \mathrm{mts}$. de altura aproximadamente.

A lo largo de los 10 metros que tenemos documentados de la construcción de Niebla, los pilares presentan características sensiblemente diferentes; unas veces se levantan superponiendo sillares a soga de 0,55 mts. de ancho, uno por hilada, y otras se combinan de forma más irregular. El desarrollo de la excavación sólo ha permitido documentar de esta construcción, hasta el momento, un paramento; el opuesto permanece oculto bajo edificios romanos, a excepción de un tramo de mampostería. Junto a este tramo se realizó un pozo de sondeo que nos permitió comprobar que, en el que suponemos paramento interior, los mampuestos estaban minuciosamente calzados con ripio y su cara externa había sido retocada para conseguir una pared regular. No sabemos si un trabajo de estas características se hizo sólo pensando en dotar de solidez a una obra cuya superficie exterior iría finalmente revocada o si, por el contrario, se perseguía un efecto estético sobre un paramento que iba a quedar visto; no encontramos aquí restos de enlucido alguno. Esta técnica supone también una pervivencia de conocimientos de albañilería más antiguos, de los que hay ejemplos en el mismo yacimiento al menos desde el siglo IV a.C.; técnica que podemos reconocer también en los tramos de mampostería del muro de pilares de Carmona y en otras estructuras descubiertas en distintos trabajos de excavación realizados en la misma plaza del Higueral ${ }^{9}$, o en su entorno inmediato (cf. Pellicer y Amores, 1985: 72 y láms.I,2 y II,1). En otro lugar (Belén y Escacena, e.p.a) hemos explicado que es el aspecto general de estas obras, más que los detalles, el que nos lleva a defender para todas ellas un origen común, que para nosotros está en el Próximo Oriente, como el de los muros de pilares (cf. Hamilton, 1933: lám. XXI,1; Yadin y otros, 1961: lám. CXXXVI,1; Chambon, 1984: 29, fig. 6a y láms. 24, 29a y 34a). Con los colonos fenicios debieron llegar a Andalucía Occidental todos estos conocimientos técnicos, que se aplican tanto a la construcción civil como a las grandes obras defensivas. La información más completa sobre su empleo en estos territorios peninsulares nos la ofrece el poblado fenicio del Castillo de Doña Blanca. Tendremos que esperar a la publicación de síntesis de las distintas campañas de excavación, actualmente en preparación, para conocer con exactitud en qué momento de la vida del poblado se empieza a construir con mampostería regular calzada con ripios, pero podemos afirmar que en la última fase del mismo, fechada durante los siglos IV-III a.C., todas las obras del poblado (caśas, almacenes y muros de defensa) se construyeron con esta técnica que hemos identificado también en los restantes lugares citados.

Las obras de Niebla y Carmona presentan otros rasgos comunes. Ambas están exentas y, por tanto, los dos paramentos quedan vistos. La diferencia entre la envergadura de una y de otra, seguramente guarda relación con la función que desempeñaron. Pero hay algunos detalles relacionados con sus dimensiones que no queremos dejar de comentar. El muro de Carmona tiene 1,10 mts. de ancho, exactamente el doble que el de Niebla. Esta unidad de 0,55 mts. corresponde también, aproximadamente, al ancho de uno de los sillares del primero ${ }^{10}$ y supone 2 veces y media la longitud de otro que mide 1,38 mts. Podríamos pensar en simples coincidencias si no fuera porque está comprobado el uso en la arquitectura fenicia de un codo de 0,55 mts. En opinión de Jodin (1975: 73), esta unidad de medida pervivió en las antiguas colonias occidentales hasta época romana, como él mismo ha podido comprobar en Mogador y Volubilis.

9. Pudimos comprobar la existencia de una estructura construida de esta forma en nuestra visita a las excavaciones que $\mathrm{M}^{\mathrm{a}}$ S. Gil de los Reyes dirigió en 1987 en el solar $n^{\circ} 3$ de la Plaza del Higueral. De dichas excavaciones se ha publicado un informe breve en el que identificamos el muro en cuestión con el que llaman 3/A, fechado entre fines del VI y primera mitad del V a.C., por la identidad que su descripción presenta con la que Pellicer y Amores dan para el Muro I del corte CA-80/A, que está también levantado con la misma técnica : cf. Gil de los Reyes y otros, 1990: 583 con Pellicer y Amores, 1985: 72.

10. Tiene, según los excavadores, $0,56 \mathrm{mts}$. 
En la Península Ibérica está por hacer un estudio de los sistemas metrológicos que se usan en la arquitectura prerromana de las distintas áreas culturales, pero un simple examen superficial permite augurar resultados interesantes de un análisis más detenido. Veamos sólo dos ejemplos más. El muro I, al que nos hemos referido más atrás, que Pellicer documentó en el corte CA-80/A de Carmona, a pocos metros de la plaza del Higueral, tiene una fosa de cimentación de 1,10 mts., y su anchura se ha calculado en 0,80 , medida que se aproxima mucho a la de $0,825 \mathrm{mts}$., que constituye un pie de $0,55 \mathrm{mts}$. y medio (Pellicer y Amores, 1985: 72). Finalmente, algunas de las casas de Chorreras, una de las fundaciones fenicias más antiguas en las costas de Andalucía, tienen muros de 0,45 y 0,55 mts. (Aubet y otros, 1979: 99), medidas que coinciden con los dos codos, pequeño y grande, que Jodin (1975: 73) documentó en las ciudades del Marruecos púnico" ${ }^{11}$.

Como sucede en otros territorios en los que las tradiciones constructivas de origen fenicio estuvieron muy arraigadas (Elayi, 1980: 179), también en Andalucía occidental podemos rastrear todavía en época imperial romana el empleo combinado de sillares y mampostería en paños alternos. El uso de esta técnica está bien documentado, una vez más, en Niebla y en Carmona, sobre todo, aunque se conocen también ejemplos en Peñaflor, sobre la orilla derecha del Guadalquivir (Keay, 1991: 281, lám. 2) y en la colonia malagueña del Cerro del Mar'2. En el asentamiento de la provincia de Huelva citado poco más arriba, se excavaron hace unos años ${ }^{13}$ varias estancias amplias cuyos muros alternan paños regularmente espaciados de mampostería y sillares. Éstos se superponen de uno en uno para formar el pilar, como ocurre también en estructuras de Carmona del siglo I d. C. (Cardenete y otros, 1991: 563-564). En ambos casos los sillares son más cortos que en épocas precedentes y prácticamente cuadrados.

\section{CONCLUSIONES}

Recientemente hemos estudiado los muros de pilares documentados hasta el momento en Andalucía occidental, en un trabajo que supone una primera valoración de esta técnica arquitectónica fuera de los sitios considerados tradicionalmente asentamientos fenicios. Ello nos exime de entrar en pormenores ya tratados allí (Belén y Escacena, e.p.).

El de Carmona es hasta ahora el ejemplo situado más al interior de las tierras del Guadalquivir. Esto no tendría mayor importancia si no fuera por la fuerte tradición oriental que muchas de las manifestaciones arqueológicas de esa localidad sevillana han mostrado. Recordemos a este respecto que ya Bonsor (1899) defendió la instalación de colonos semitas en la zona de Los Alcores, y que la necrópolis de la Cruz del Negro, pródiga en manifestaciones rituales y materiales de carácter foráneo, ha llegado a convertirse recientemente en el ariete de una recuperada interpretación histórica sobre el papel de los fenicios en el mundo tartesio (González Wagner, 1986: 146-147). Por otra parte, se ha afirmado que la Carmona prerromana, tras un período de fuerte influencia oriental en el que no se excluyen aportes humanos, «acabó por ser prácticamente púnica» (Bendala, 1992: 21), y se han reconocido las señas de tal identidad en la arquitectura defensiva (Jiménez, 1989: 182-187) y, sobre todo, en el campo religioso. La imagen de Melqart se reprodujo en la moneda de la ciudad (Tsirkin, 1985: 257; Blázquez, 1986: 176) y las tradiciones funerarias siguieron manifestándose con fuerza en época romana (Bendala, 1976: 38 y ss.).

11. El codo pequeño tiene exactamente 0,46 mts: Jodín, 1975:14.

12. Agradecemos la información al Prof. D. Oswaldo Arteaga.

13. Estructuras documentadas en trabajos dirigidos por D. Mariano del Amo, todavía inéditas. 
Si el muro de pilares del Cabezo de San Pedro en Huelva se interpreta como presente introductorio de los colonos fenicios hacia la sociedad indígena, el de Carmona podría revelar que en el siglo VI a.C. la comunidad tartesia participaba ya de una serie de técnicas constructivas extrañas a las tradiciones locales de finales de la Edad del Bronce. Este acervo puede interpretarse de dos formas distintas, sin que existan de momento, a nuestro entender, razones de mayor peso para defender la una y negar la otra. De un lado, podría pensarse que fueron los Turdetanos de Carmona quienes, aculturados por el impacto de la colonización oriental, adoptaron dichos modelos arquitectónicos para sus edificios. Frente a esta interpretación, quienes hayan visto en todos y cada uno de los rasgos de orientalismo antes enumerados la manifestación directa de un claro asentamiento de colonos semitas en la ciudad desde la primera Edad del Hierro, podrán sumar a sus razones un argumento más de dicha presencia, en cuanto que el muro de pilares que nos ocupa podría considerarse un elemento constructivo levantado por y para gentes extranjeras de raigambre fenicia afincadas en la Carmona tartesia, que habrían llegado a la zona con intenciones de establecerse para explotar con fines agropecuarios su rica vega.

Parece evidente que, de momento, la investigación carece de los mecanismos necesarios para apoyar una tesis o la contraria; porque, si bien la literatura arqueológica e histórica sobre la Protohistoria del Bajo Guadalquivir se ha mostrado pródiga en partidarios de ambas, las razones que avalan a unos y a otros han estado supeditadas más a modas historiográficas sobre el papel de lo autóctono y de lo alóctono en la formación de las culturas que a verdaderos pilares epistemológicos. Aún así, y siendo nosotros partidarios de una tradición científica que pretende recuperar la reconstrucción histórica que admite la presencia de colonos orientales en el interior de los territorios tartesios, vemos la dificultad de decantarnos por considerar este muro una manifestación inequívoca de dicha presencia. En cualquier caso, no deja de ser significativo que hasta el momento los muros de pilares se hayan documentado en asentamientos en los que, por más de una razón, se ha considerado la presencia física y estable de grupos de población de origen oriental más o menos numerosos.

\section{BIBLIOGRAFÍA}

ARRIBAS Y ARTEAGA (1975): «El yacimiento fenicio en la desembocadura del río Guadalhorce». Cuadernos de Prehistoria de la Universidad de Granada. Serie Monográfica $n^{\circ} 2$.

AUBET, $M^{a}$. E. (1989): «La Mesa de Setefilla: la secuencia estratigráfica del corte 1» en M.E.AUBET (dtor.), Tartessos. Arqueología Protohistórica del Bajo Guadalquivir: 297-338. Sabadell, Ed. Ausa.

AUBET, Ma.E. y otros. (1983): La mesa de Setefilla. Lora del río (Sevilla). Campaña de 1979 (Excavaciones Arqueológicas en España 122). Madrid.

AUBET,M ${ }^{a}$ E., MAAS-LINDEMANN,G. y SCHUBART,H. (1979): «Chorreras. Un establecimiento fenicio al Este de la desembocadura del Algarrobo», Noticiario Arqueológico Hispánico, 6:91-138.

BELÉN, M. (1976): «Estudio y tipología de la cerámica gris en la provincia de Huelva», Revista de Archivos, Bibliotecas y Museos LXXIX, $n^{\circ} 2: 353-388$.

BELÉN, M. y ESCACENA, J.L. e.p.a: «Las comunidades prerromanas de Andalucía occidental», $I$ Congreso de Paletnología de la Península Ibérica (Madrid, Universidad Complutense, 1989). T.P 50. e.p.b: Niebla (Huelva). Excavaciones junto a la Puerta de Sevilla (1978-1982). La Cata 8, Huelva Arqueológica XII.

BELÉN, M. y otros. (1983): «Excavaciones en Niebla (Huelva)», XVI C.N.A. Cartagena,1982/Zaragoza: 971-982. 
BENDALA, M. (1976): La necrópolis romana de Carmona (Sevilla). Publicaciones de la Excma. Diputación Provincial, Seccción: Historia. Serie $1^{a} n^{\circ} 11$.

1992: «Tartessos: ¿concierto o desconcierto?». Arqrítica, 3: 20-22.

BLÁZQUEZ, J.M ${ }^{\mathrm{a}}$ (1986): «El influjo de la cultura semita (fenicios y cartagineses) en la formación de la cultura ibérica», en DEL OLMO,G. y AUBET, Mª E. (eds.): Fenicios en la Península Ibérica, 2: 163 178. Sabadell, Ed. Ausa.

CARDENETE,R. y otros. (1990): «Excavaciones arqueológicas de urgencia en el solar de la c/Higueral 2, Carmona (Sevilla)», $A A A^{\prime} 88$,III:257-263. Sevilla.

CARDENETE,R. y otros. (1991): «Excavaciones arqueológicas de urgencia en el solar de la C/Costanilla Torre del Oro s/nº. Carmona (Sevilla)», $A A A^{\prime}$ '89,III: 563-574. Sevilla.

CARO, A. (1989): Cerámica gris a torno tartesia. Cádiz, Universidad de Cádiz.

CARRIAZO, J. de M. y RADDATZ, K. (1960): «Primicias de un corte estratigráfico en Carmona», Archivo Hispalense $2^{\mathrm{a}}$ época, $\mathrm{n}^{\mathrm{o}}$ 103-104.

CUADRADO, E. (1969): «Origen y desarrollo de la cerámica de barniz rojo en el mundo tartésico», $V$ S.I.P.P.: Tartessos, Barcelona, 257-290.

CHAMBON,A. (1984): Tell El-Far'ah 1. L'Age du Fer. París, Eds. Recherches sur les Civilisations (Mémoire $\mathrm{n}^{\circ} 31$ ).

CHAVES, F. y DE LA BANDERA, M.L. (1986): «Figürlich verzierte Keramik aus dem GuadalquivirGebiet. Die Funde von Montemolin (bei Marchena, Prov. Sevilla)». Madrider Mittelilungen 27: 117 150 .

e.p.: «Problemática de las cerámicas orientalizantes y su contexto», V Congreso de Lenguas y Culturas Paleohispánicas.

DOMÍNGUEZ DE LA CONCHA, M.C. y otros. (1988): «Cerro de la Cabeza (Santiponce, Sevilla)», N.A.H., 30, 119-186.

ELAYI, J. (1980): «Remarques sur un type de mur phénicien», $R S F$, VIII, 2:165-180.

ESCACENA, J.L. (1979-80): «Cerámica ibérica de Setefilla (Sevilla)», Pyrenae 15-16, 181-210.

(1987a): «El poblamiento ibérico en el Bajo Guadalquivir», Iberos. Actas de las I Jornadas sobre el Mundo Ibérico / Jaén, 1985: 273-298. Jaén.

(1987b): Cerámicas a torno pintadas andaluzas de la segunda Edad del Hierro. (Edición en microfichas). Cádiz.

ESCACENA, J.L. y BELEN, M. (1991): «Sobre la cronología del horizonte fundacional de los asentamientos tartésicos», Cuadernos del Suroeste 2: 9-42. Huelva.

FERNÁNDEZ JURADO, J. (1986): «Economía tartésica: minería y metalurgia», en Huelva en su Historia. Miscelánea Histórica: 149-170. Sevilla.

(1988-1989): Tartessos y Huelva. Huelva Arqueológica X-XI,1. Huelva.

(1991): «Influencia fenicia en la arquitectura tartéssica», Actas Jornadas de Arqueología feniciopúnica I-IV (Ibiza 1986-89): 169-173. Ibiza.

GIL DE LOS REYES,Ma S., GOMEZ SAUCEDO,M ${ }^{a}$ T., y RODRÍGUEZ, I. (1990): «Carmona protohistórica, (Sevilla): Intervención en la Plazuela del Higueral no $3 », A A A^{\prime}$ '87, III: 581-585.

GONZALES WAGNER, C (1986): «Notas en torno a la aculturación de Tartessos». Gerion, 4: 129-160. Madrid. Univ. Complutense.

HAMILTON,R.W (1933): «Tell Abu Hawam. Interim report», The Quarterly of the Department of Antiquities in Palestine, III/2: 74-80.

JIMÉNEZ, A. (1989): La Puerta de Sevilla en Carmona. Sevilla, Consejería de Obras Públicas y Transportes. 
JODIN,A (1975): Recherches sur la metrologie du Maroc Punique et Hellénistique. Tánger, Ed. Marocaines et Internationales.

KEAY,S. (1991): «Peñaflor (La Viña). Informe preliminar», $A A A^{\prime} 89$,II: 289-284. Sevilla.

MURILLO, J.F. (1989): «Cerámicas tartésicas con decoración orientalizante», Cuadernos de Prehistoria y Arqueología (U.A.M.) 16: 149-167.

PELLICER,M. (1969): «Las primeras cerámicas a torno pintadas andaluzas y sus problemas», V S.I.P.P.: Tartessos, Barcelona, 291-310.

(1976-78): «Problemática general de los inicios de la iberización en Andalucía occidental», Ampurias, 38-40, 3-22.

PELLICER,M. y AMORES,F. (1985): «Protohistoria de Carmona. Los cortes estratigráficos CA-80/A y CA-80/B», Noticiario Arqueológico Hispánico, 22: 55189.

PELLICER,M., ESCACENA,J.L. y BENDALA,M. (1983):El Cerro Macareno (E.A.E. 124). Madrid.

RODERO, A. (1990): Las ánforas prerromanas en Andalucia. Madrid. Universidad Complutense. Tesis doctoral inédita.

ROOS, A.M. (1982): «Acerca de la antigua cerámica gris a torno en la Península Ibérica», Ampurias, 44, 43-70.

SCHUBART, H. (1971): «Acerca de la cerámica del Bronce Tardío en el Sur y Oeste peninsular», T.P., $28,153-182$.

SHARON,I. (1987): «Phoenician and Greek Ashlar Construction Techniques at Tel Dor, Israel», Bull. of the American Schools of Oriental Research, $\mathrm{n}^{\circ}$ 267:21-42.

TSIRKIN, J. B. (1985): «The phoenician civilization in Roman Spain». Gerion, 3: 245-270. Madrid. Univ. Complutense.

VILLANUEVA, J. (1984): Arte de Albañilería, Editora Nacional, Madrid.

YADIN, Y. y otros. (1961): Hazor III-IV. An account of the third and fourth seasons of excavations, 1957. 1958. Vol. de Láminas. Jerusalem, The Hebrew University. 

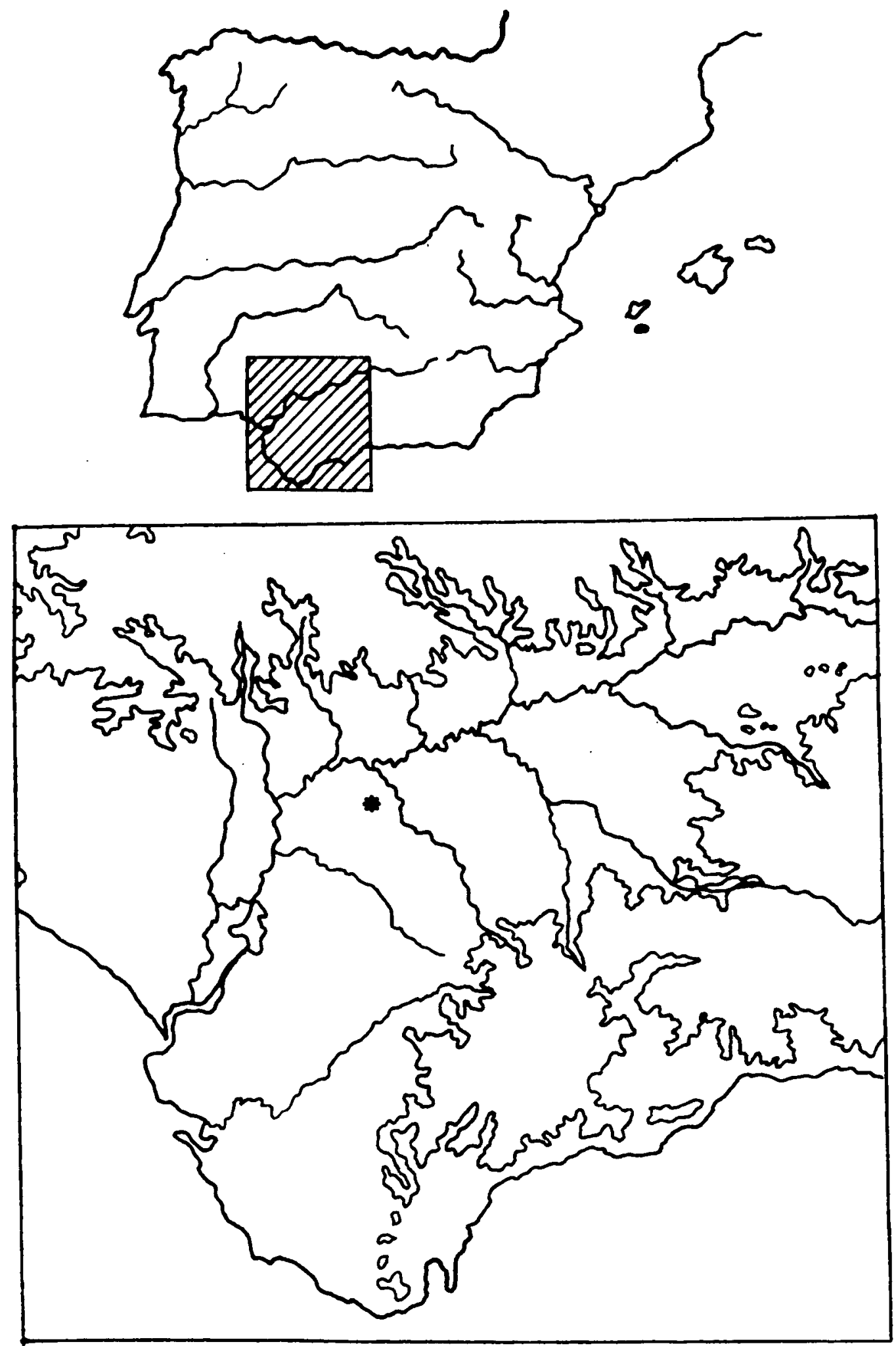

FIGURA 1: Carmona (Sevilla). 


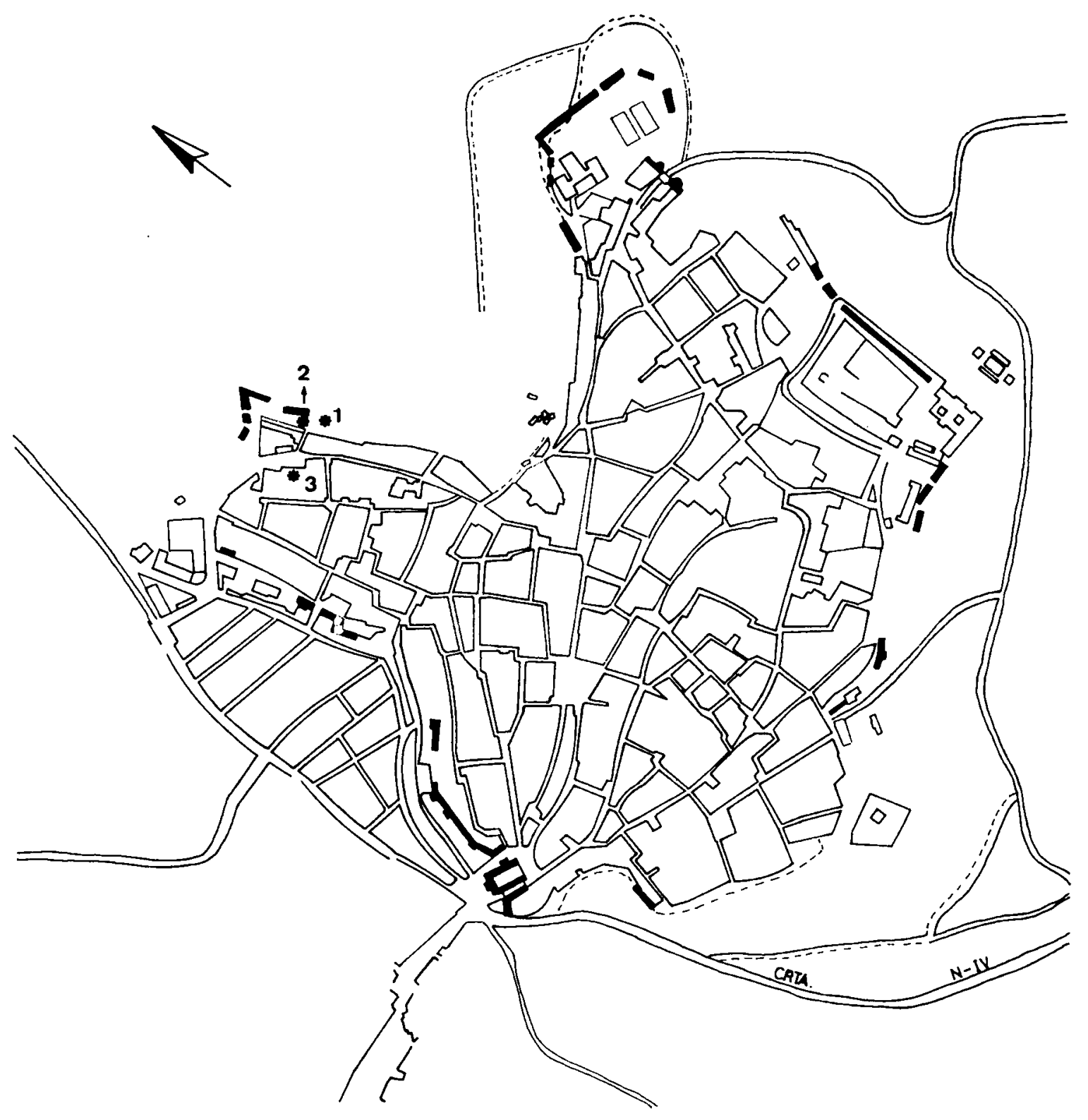

FIGURA 2: Recinto histórico de la ciudad de Carmona y situación de las excavaciones que se citan en el texto. 1: Carriazo y Raddatz, 1959; 2: Pellicer y Amores, 1980 (CA-80/A); 3: Plazuela del Higueral, 1987. 


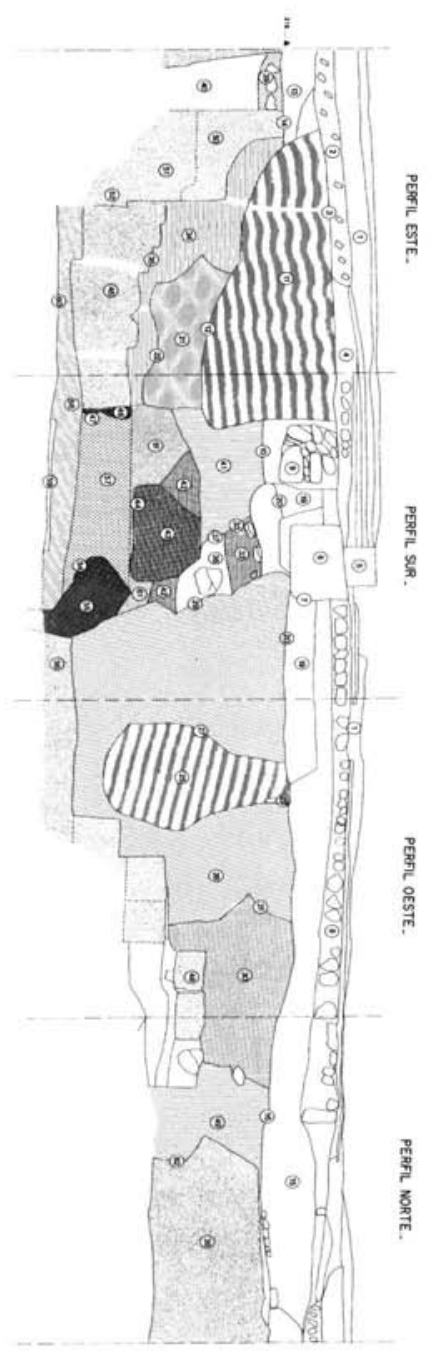

FIGURA 3: Carmona. Perfil estratigráfico del sondeo Higueral n² 2. 


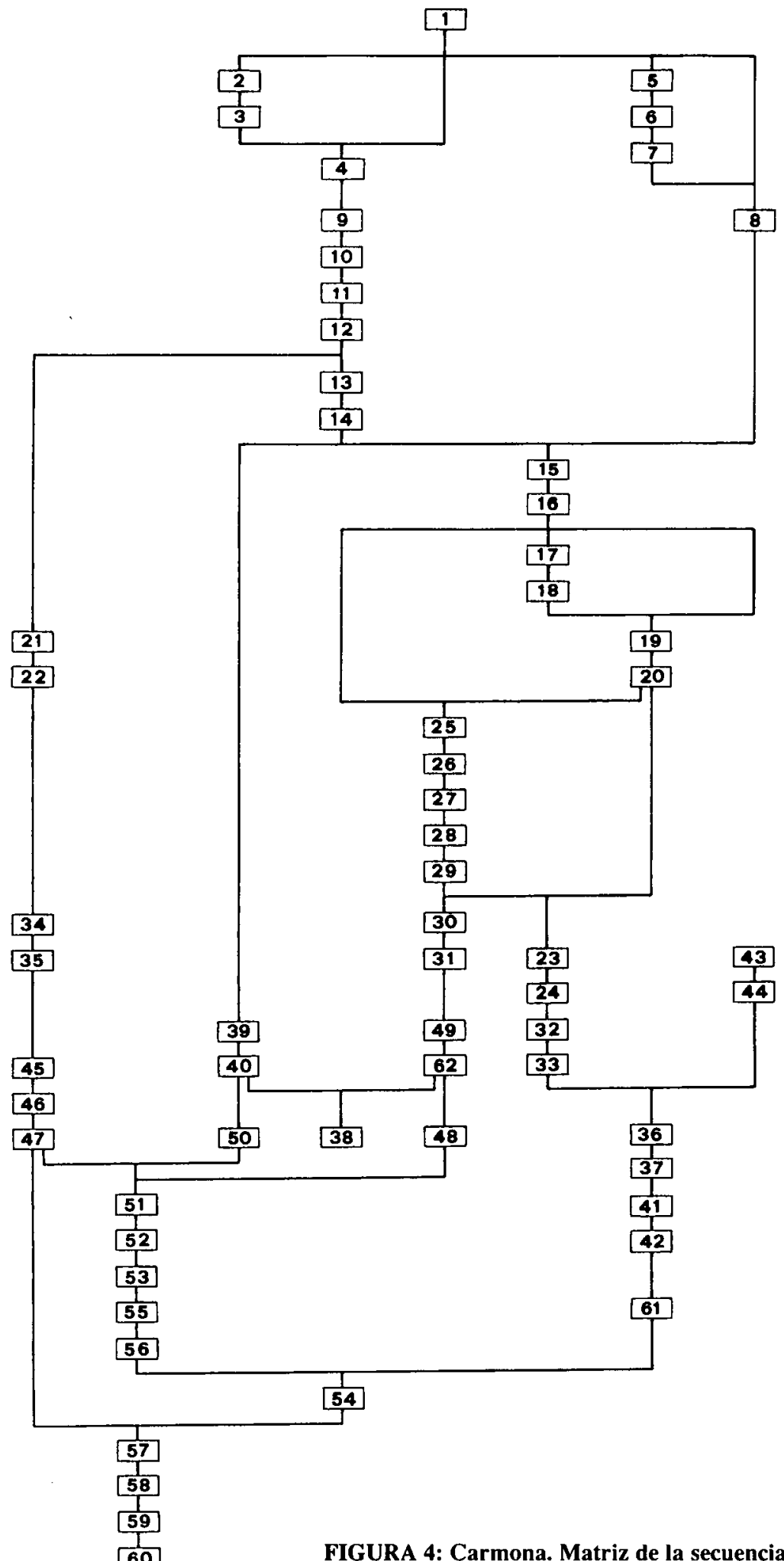

60

FIGURA 4: Carmona. Matriz de la secuencia estratigráfica de Higueral n॰ 2. 


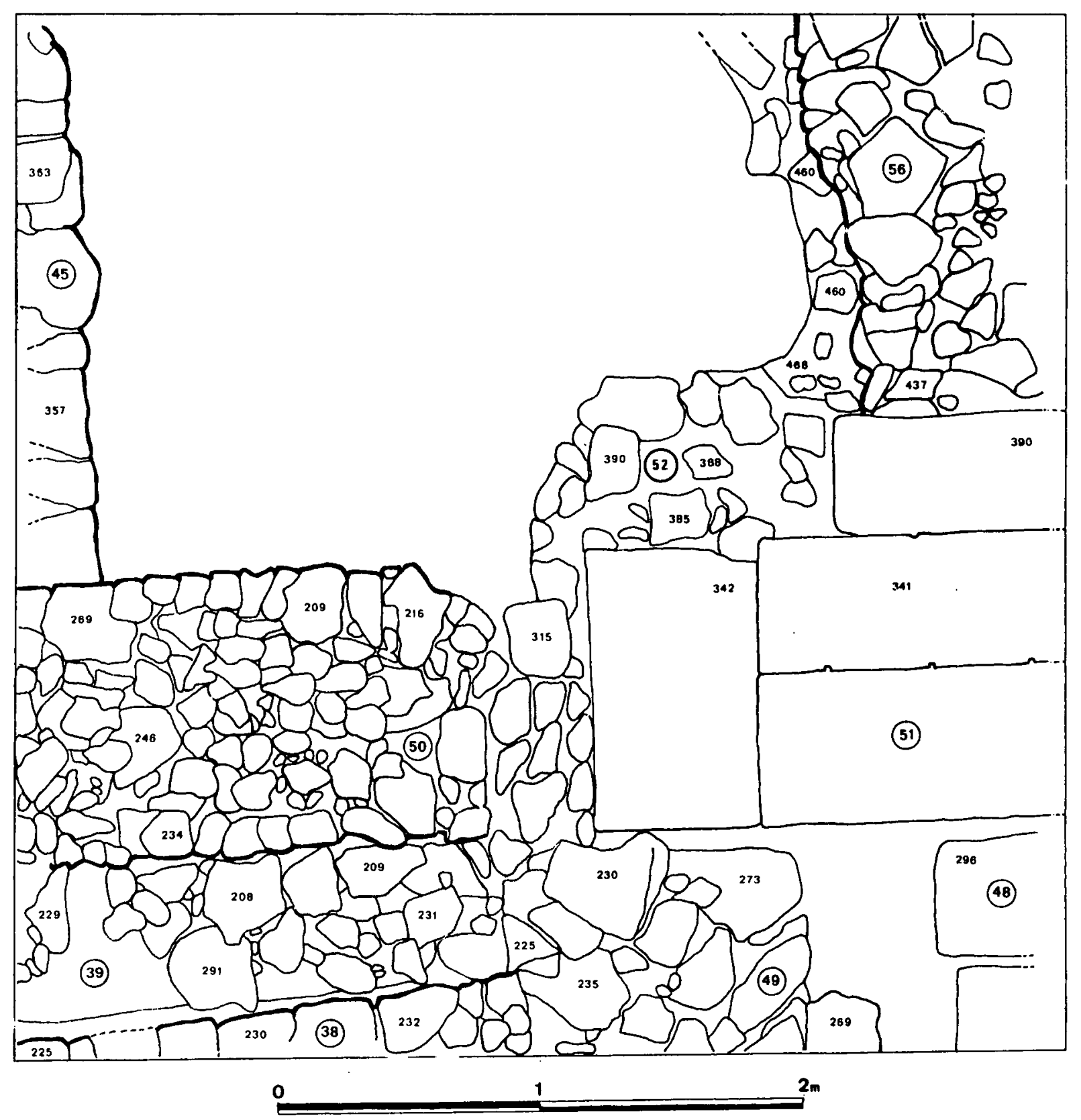

FIGURA 5: Carmona. Excavación de Higueral n.’ 2. Situación en planta del muro de pilares. 


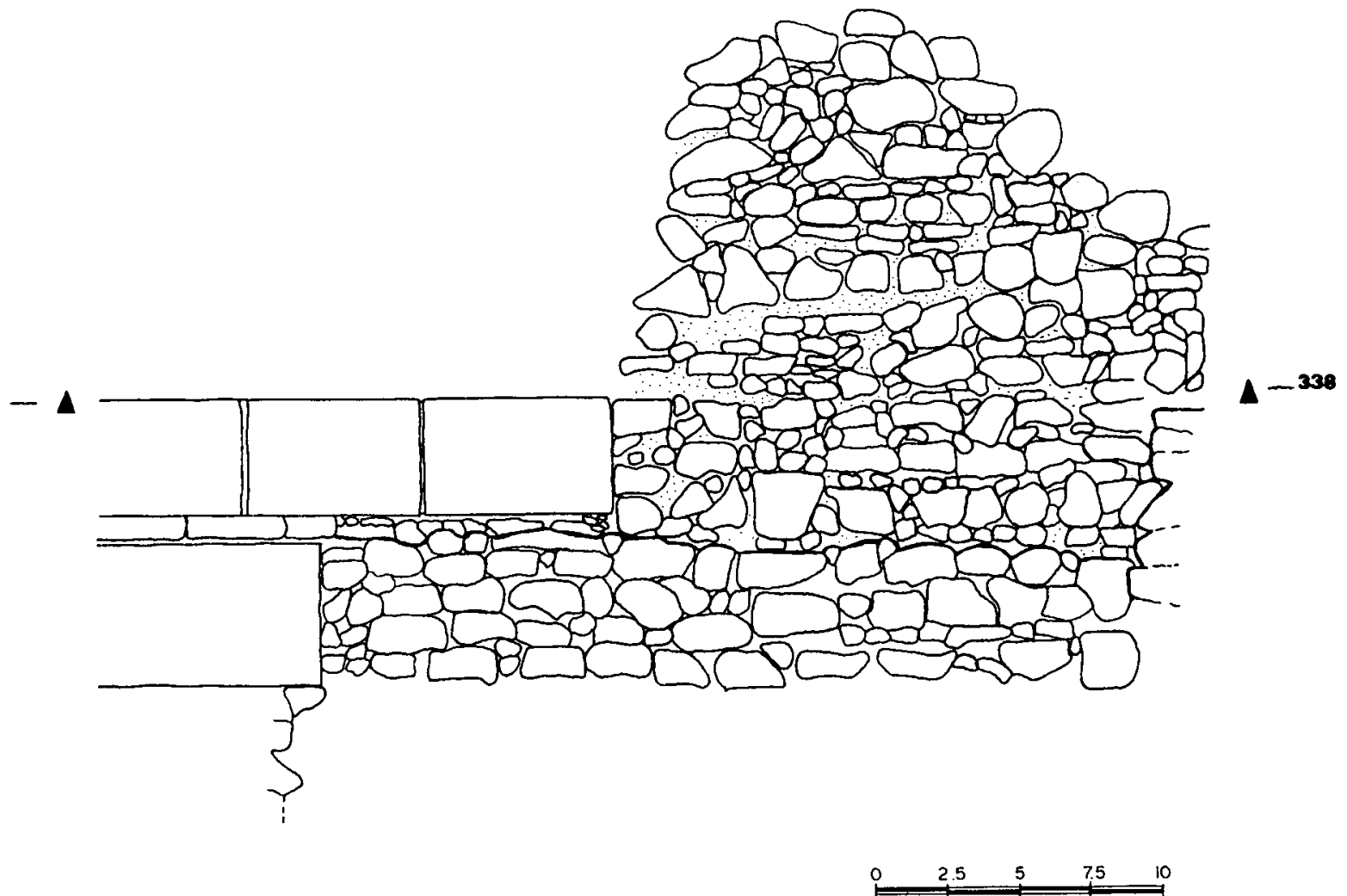

FIGURA 6: Carmona. Excavación de Higueral n 2 . Alzado del muro de pilares.
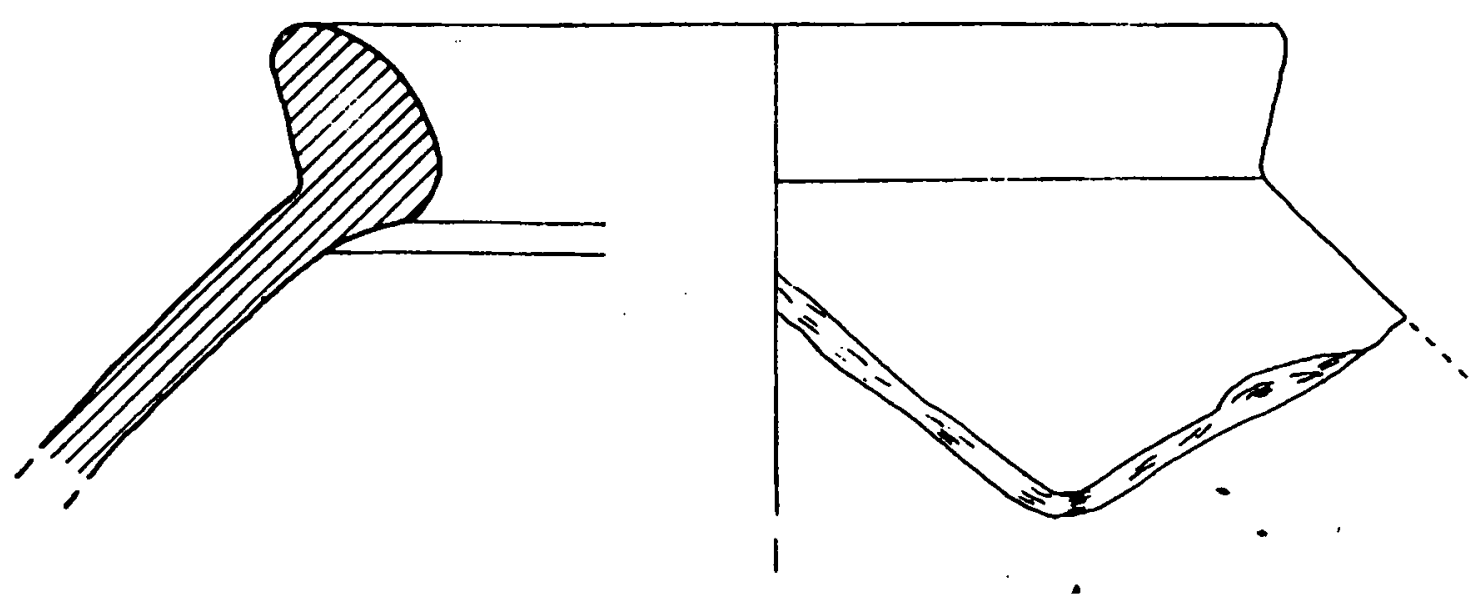

FIGURA 9: Carmona. Excavación de Higueral n. ${ }^{\circ}$ 2. UE 50. 

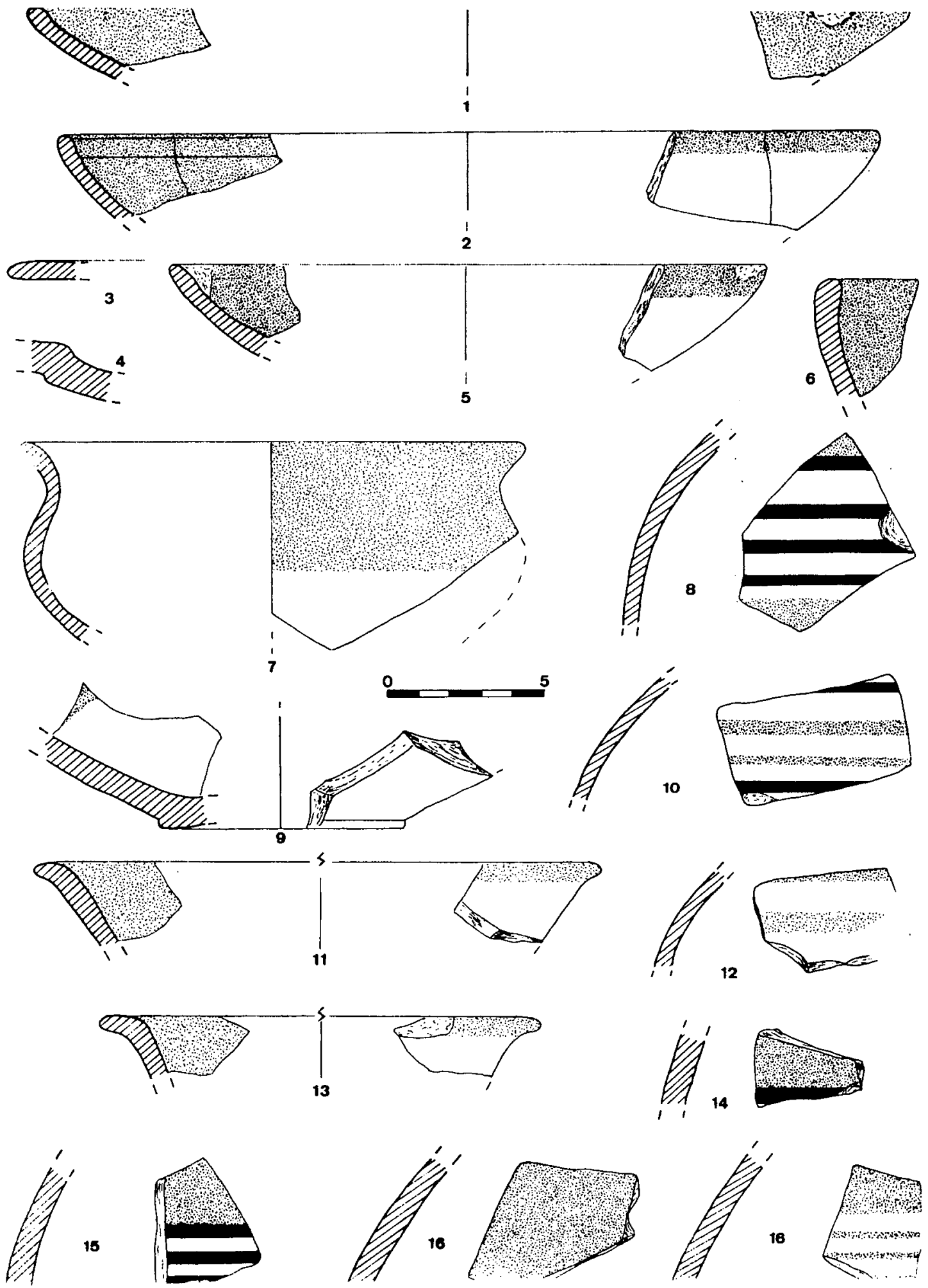

FIGURA 7: Carmona. Excavación de Higueral n. 2 . UE 61. 

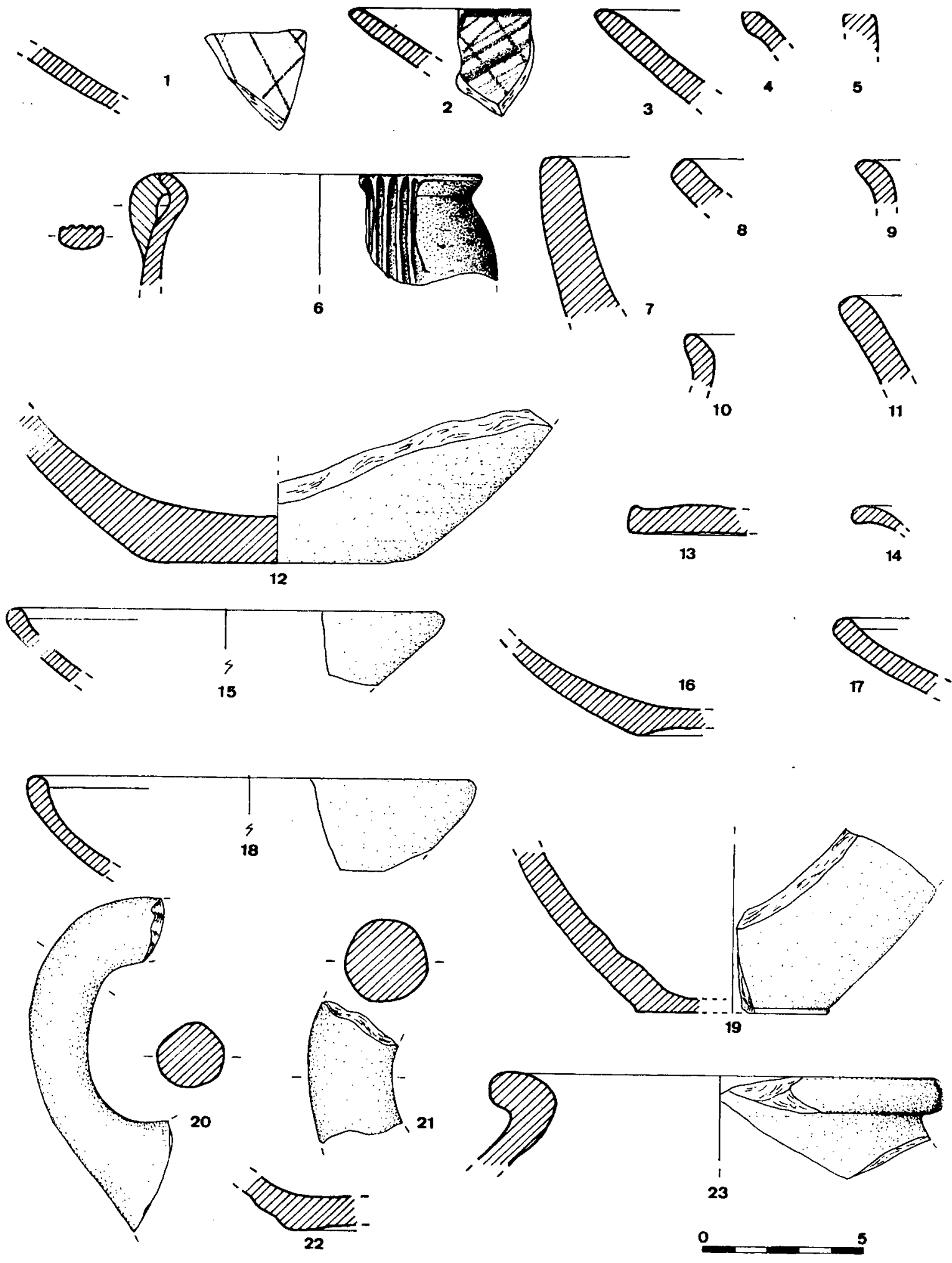

FIGURA 8: Carmona. Excavación de Higueral n. 2. UE 61. 

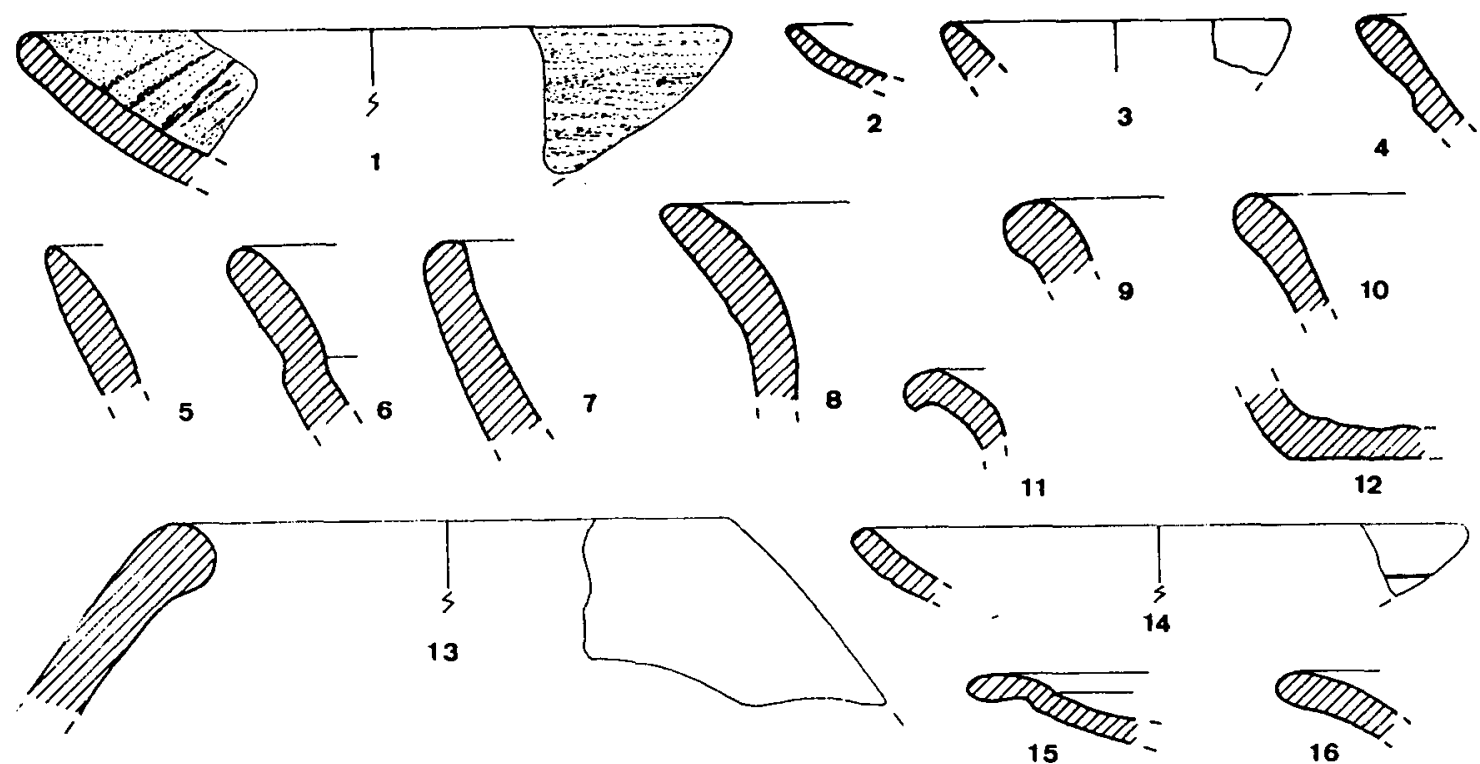

15
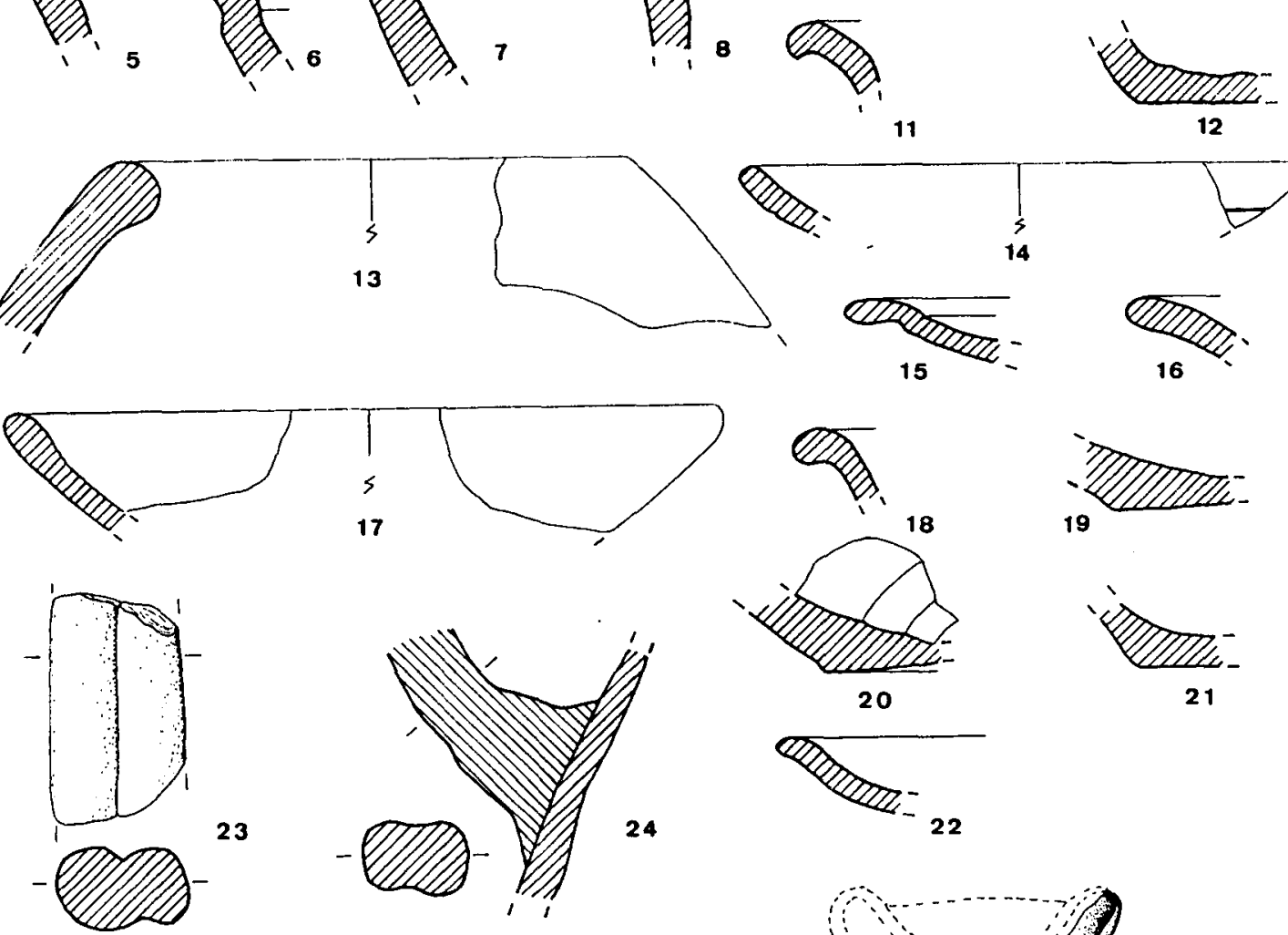

23

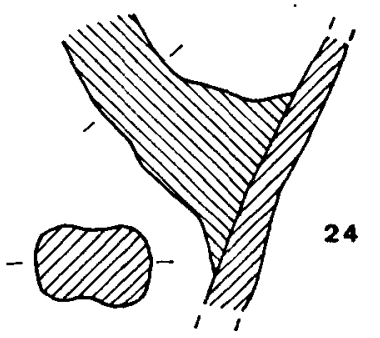

24

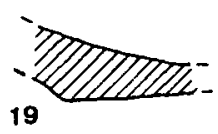

19
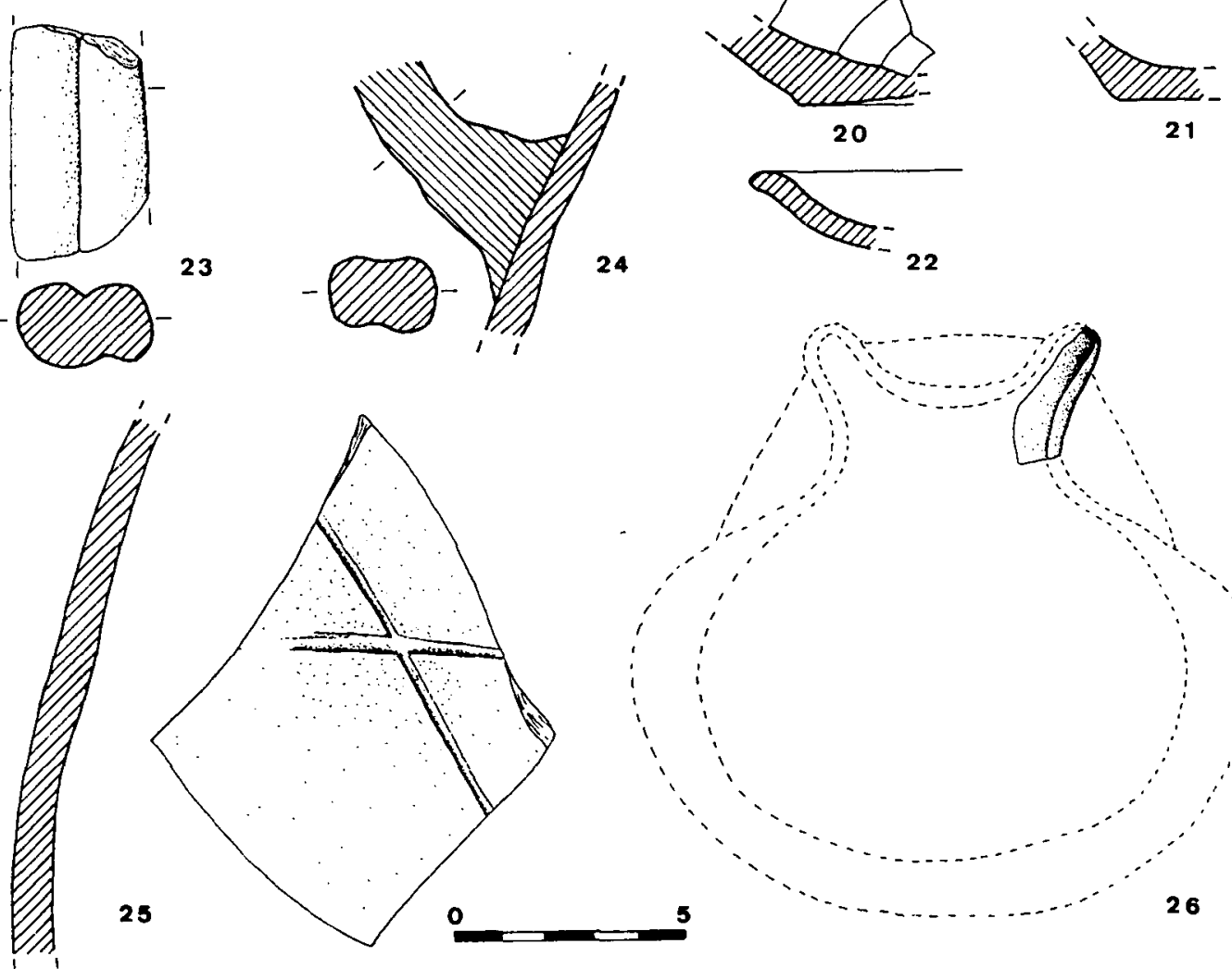

21

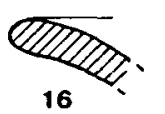

22

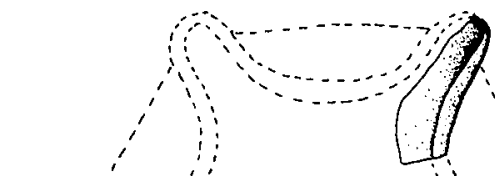

FIGURA 10: Carmona. Excavación de Higueral n.². UE 57. 

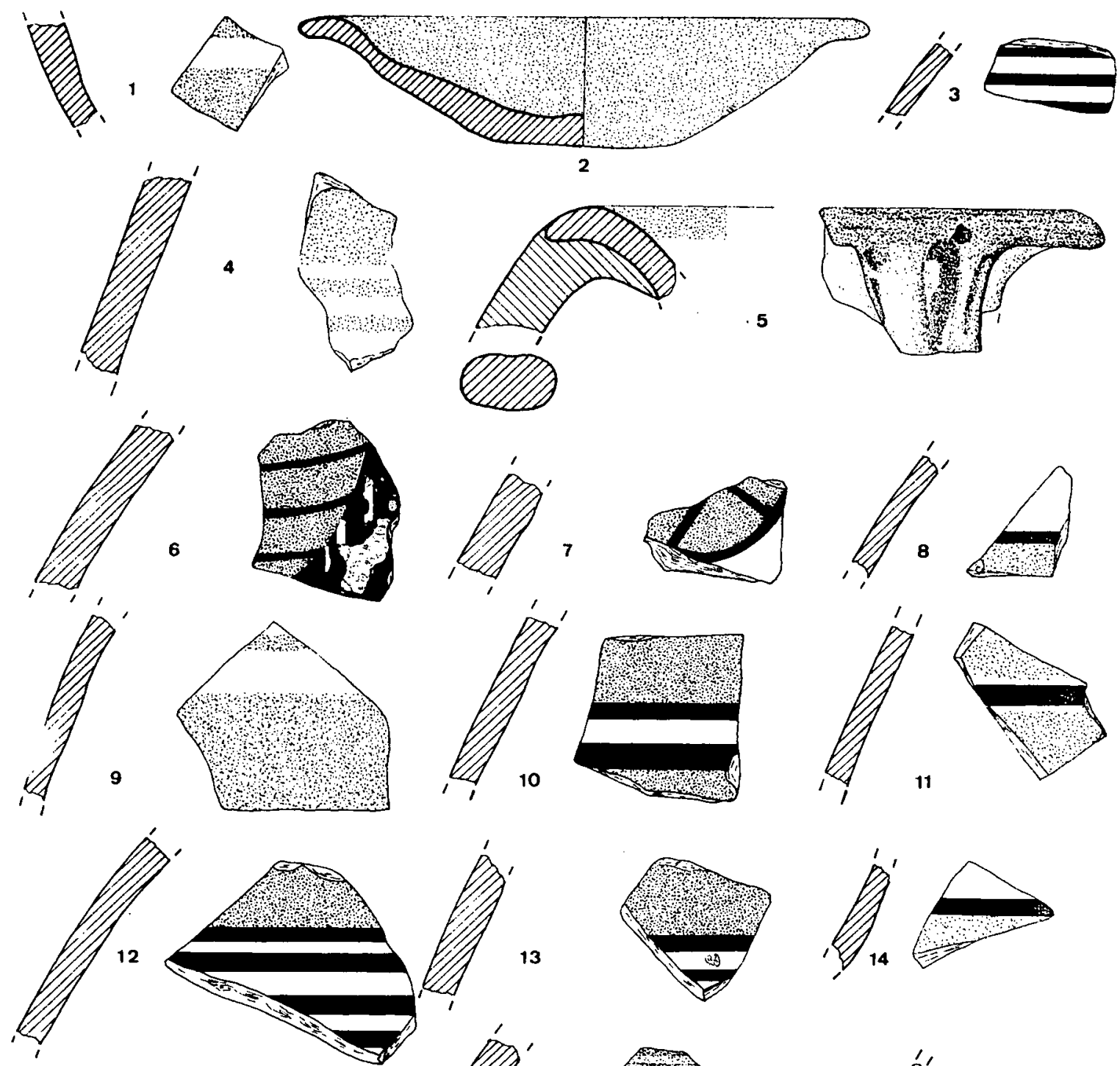

13
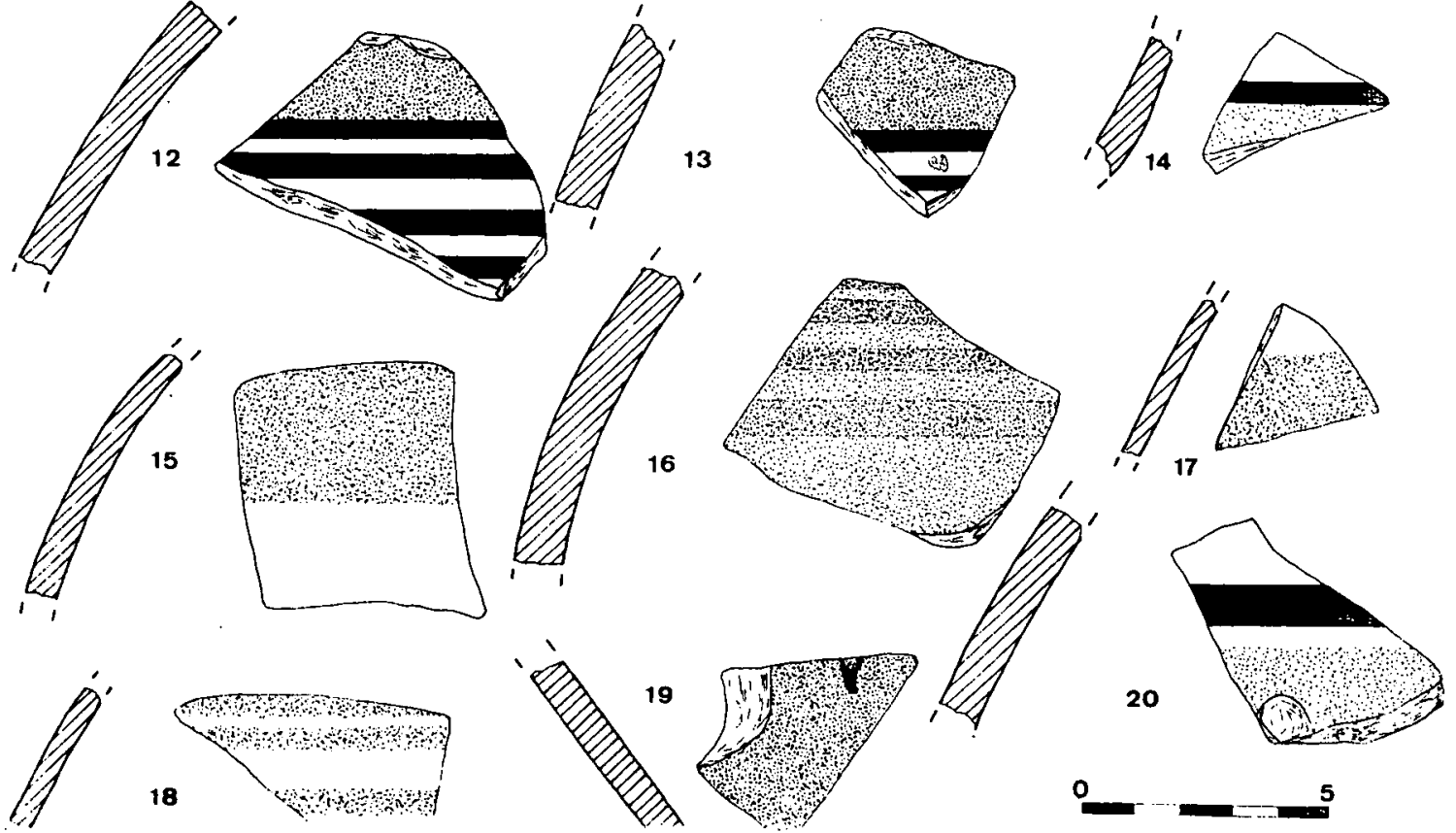

FIGURA 11: Carmona. Excavación de Higueral n. ${ }^{\circ}$ 2. UE 57.

ISSN: 1133-4525 ISSN-e: 2255-3924

http://dx.doi.org/10.12795/spal.1993.i2.09 

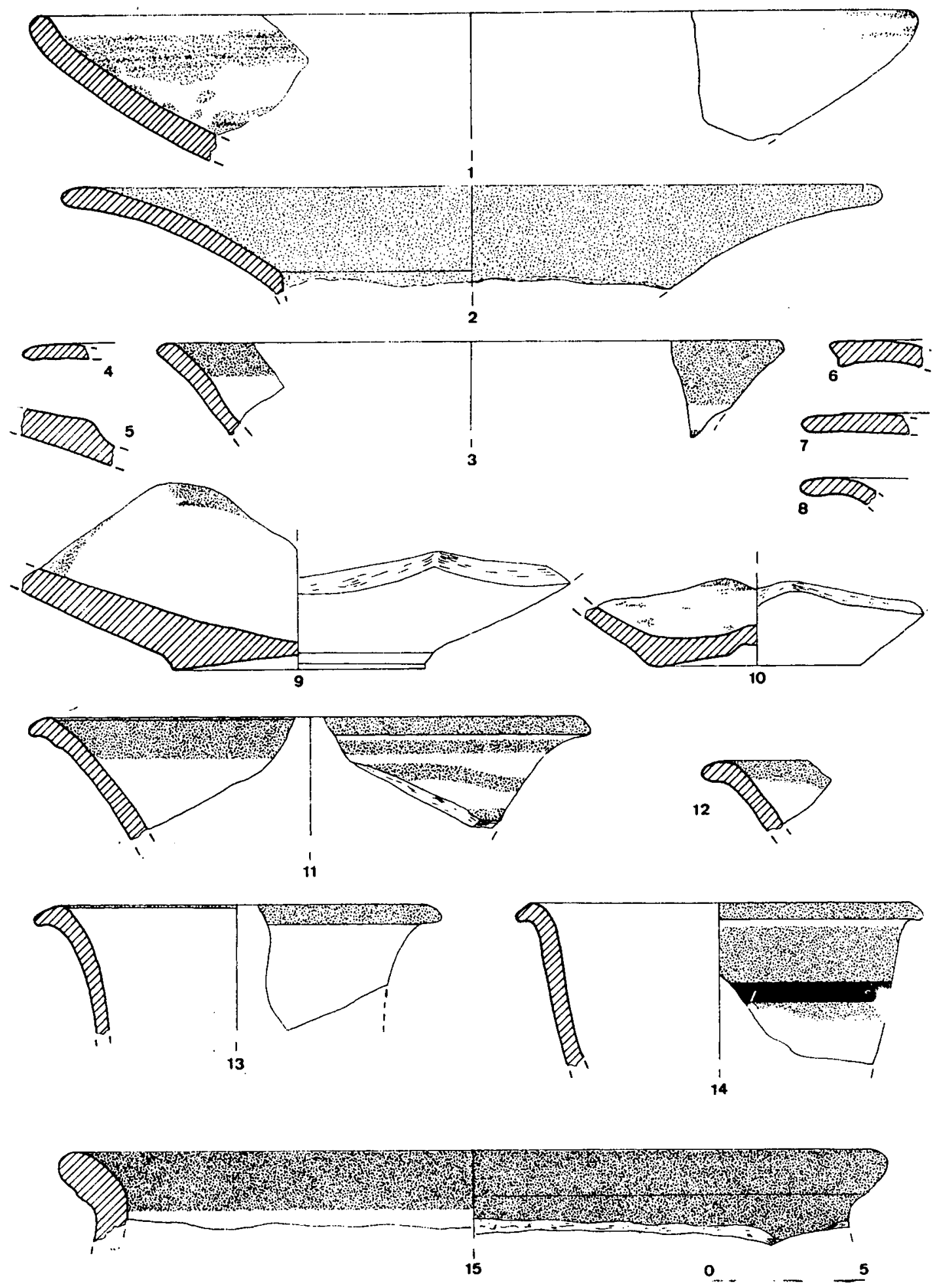

FIGURA 12: Carmona. Excavación de Higueral n. ${ }^{\circ} 2$. UE 58. 

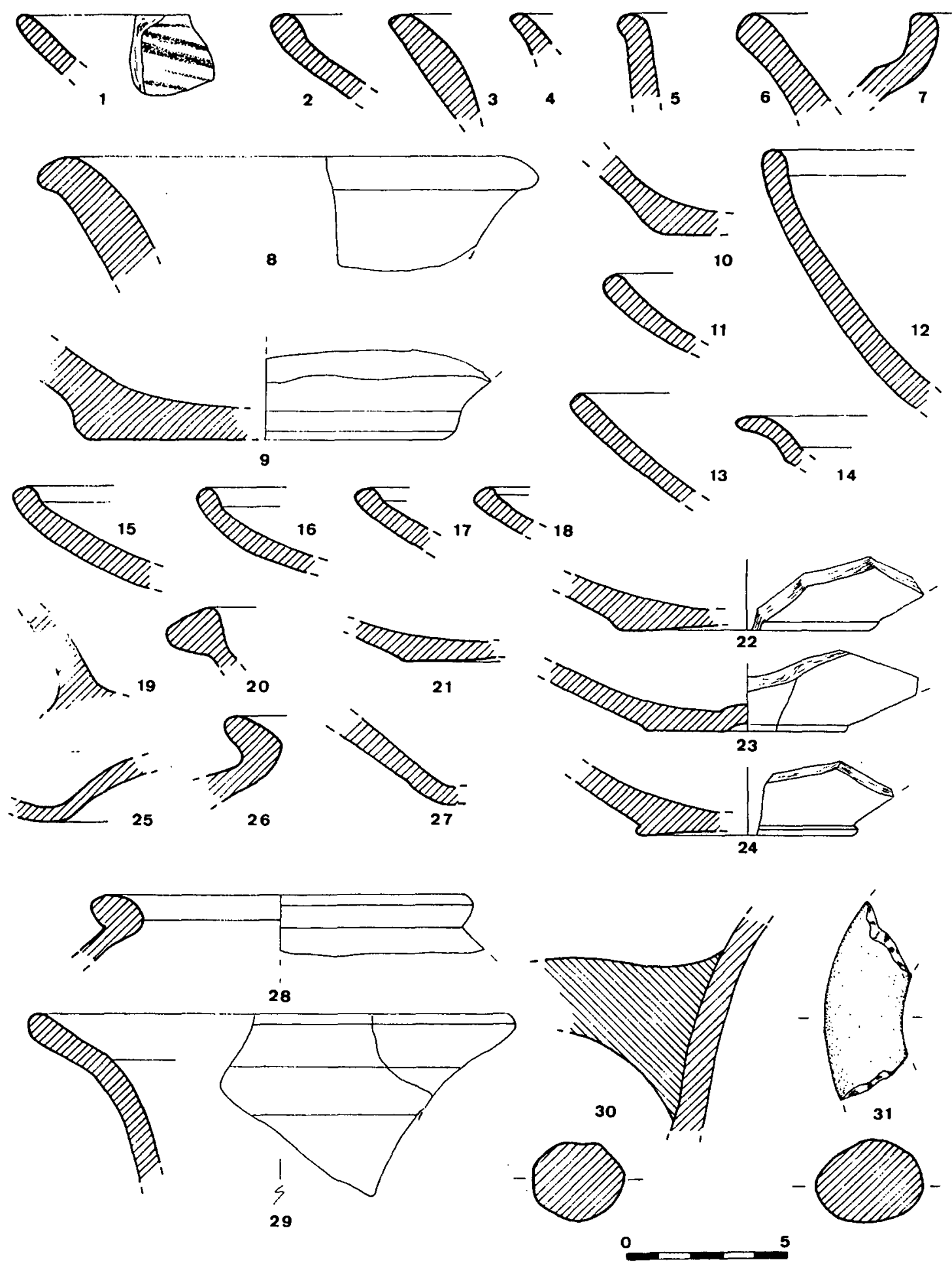

FIGURA 13: Carmona. Excavación de Higueral.n. ${ }^{2}$ 2. UE 58. 


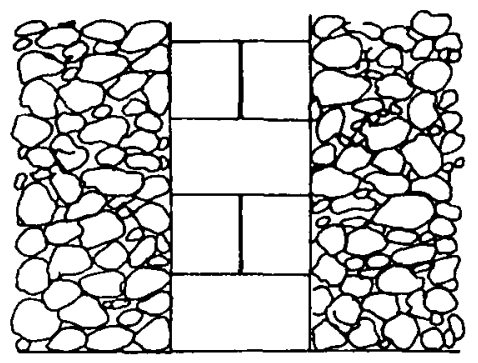

1

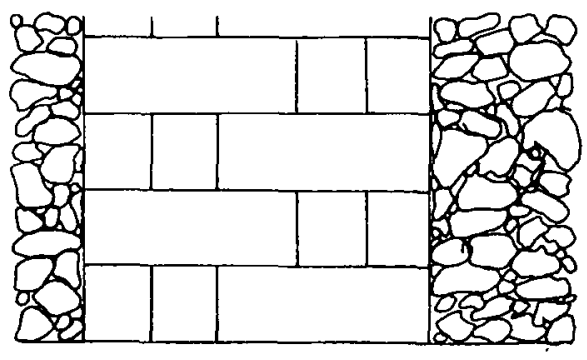

2
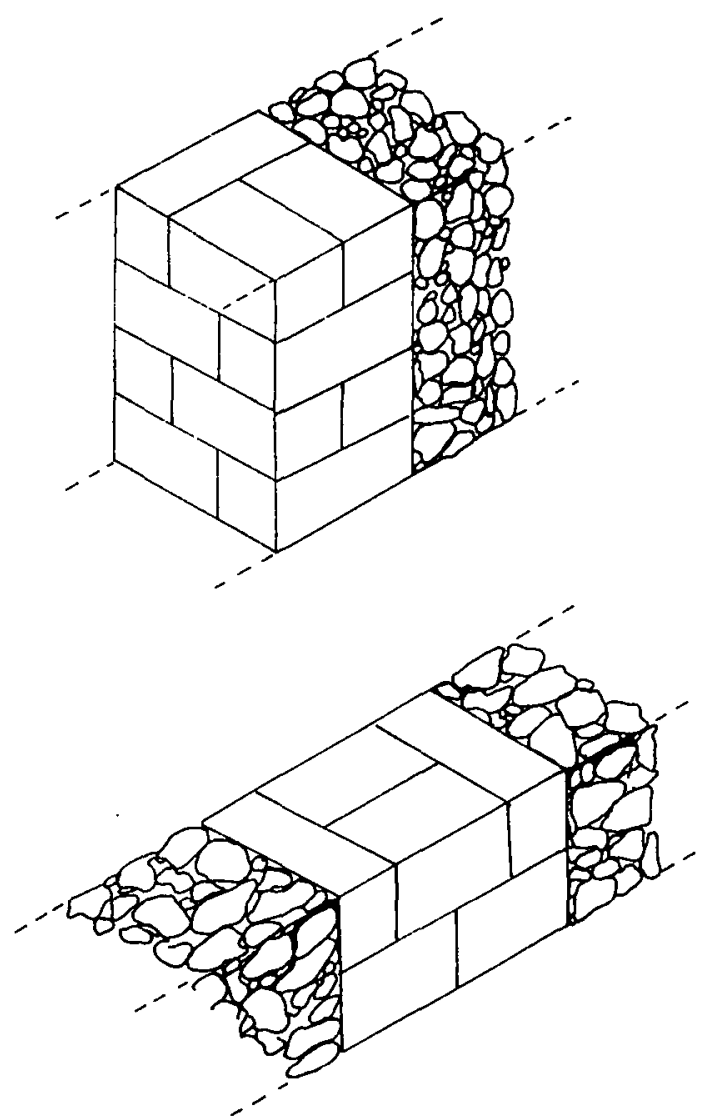

3

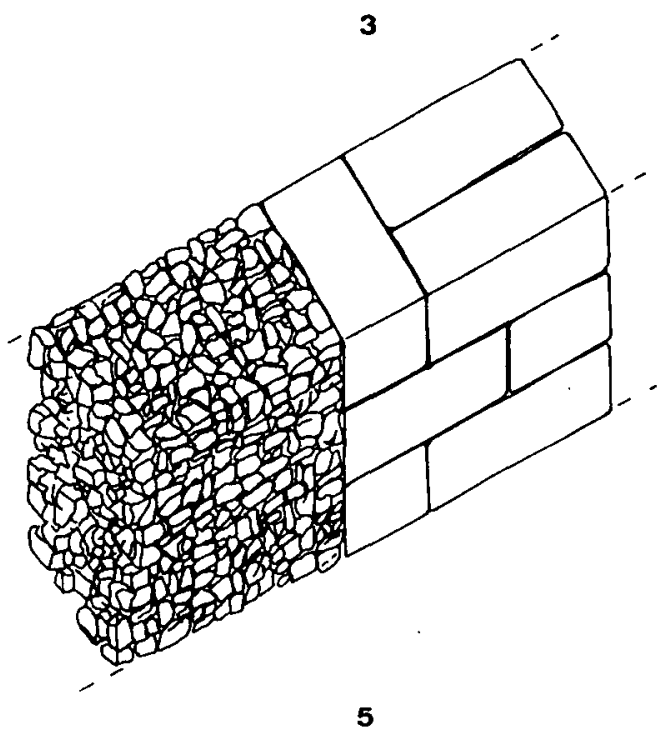

4

5

FIGURA 14: Muros de pilares. 1-4: Próximo Oriente (según Elayi, 1980).5: Carmona (reconstrucción). 